\title{
EL CUERPO en su laberinto
}

\section{Víctor Saúl Villegas Martínez}

\section{La masculinidad del Libertador se establece}

en la novela mediante numerosas marcas que aluden a dos situaciones bien diferenciadas: el esplendor de la figura de Bolívar por sus hazañas en los procesos de independencia, y la pérdida del control político debido al rechazo de sus ideas.

\footnotetext{
L
}

as novelas de Gabriel García Márquez son, sin duda, edificios narrativos complejos que encierran un universo cultural plagado de simbolismos; por ende, consisten en auténticos documentos que articulan un discurso fundacional. La novela $E l$ general en su laberinto (1989) no escapa a esta premisa y desarrolla una extensa y profunda perspectiva sobre los últimos días del Libertador Simón Bolívar, a la par que brinda un panorama sobre la reconstrucción de Hispanoamérica una vez concluidos la mayoría de los procesos de independencia.

Por este mismo contenido histórico del texto señalado, la crítica ha especulado respecto de la suave línea que separa a una novela completamente ficcional de otra con un carácter biográfico, ya que ambos factores confluyen de un modo armonioso en El general en su laberinto. Estas dos visiones o etiquetas que se le han otorgado a la novela surgen de dos aciertos correlativos de su autor: por un lado, el uso preciso de recursos narrativos para articular una historia ya conocida pero que resulta novedosa por la configuración del estilo literario y, por otro, la documentación histórica necesaria para involucrar al lector en los pormenores de la vida del Libertador venezolano. Sin embargo, más que generar polémicas, la especulación enriquece los estudios realizados sobre estas dos aristas de la novela, ya que hace hincapié en la manera magistral de enlazar los dos niveles de un texto narrativo -discurso y diégesis- para no dejar de lado ni la documentación histórica ni la dimensión estética.

El contenido histórico permite entonces reconocer un amplio universo simbólico que funciona como preámbulo a la configuración de los diferentes países hispanoa- mericanos, especialmente de Colombia y Venezuela. Como se dijo al principio, hay en la literatura de García Márquez un fuerte compromiso de carácter fundacional que permite hacer una disección de las peculiaridades de la identidad hispanoamericana -el cual es compartido con el resto de los escritores del boom-. Este acercamiento a la identidad plantea entonces una recuperación de la forma en la que es concebido el dispositivo de género, el cual ha servido no solo para configurar la concepción ideal del hombre o la mujer que se requería en las jóvenes naciones hispanoamericanas, sino para construir prácticamente todas las sociedades. Por ello, es interesante analizar cómo aparecen representados lo masculino y la figura del héroe en esta novela, ya que forman parte del género que posee Bolívar y, por ende, funcionan a manera de ejemplo para el resto de la colectividad que lo rodea.

La masculinidad del Libertador se establece en la novela mediante numerosas marcas que aluden a dos situaciones bien diferenciadas: el esplendor de la figura de Bolívar por sus hazañas en los procesos de independencia, y la pérdida del control político debido al rechazo de sus ideas. Estos dos momentos se sobreponen uno al otro para dar casi la impresión de que hay dos sujetos bien diferenciados, aunque, claro está, el objetivo del texto es dar prioridad a los últimos días de Bolívar, por lo que esa segunda etapa en la cual el Libertador inicia su lento y prolongado camino al exilio aparece descrita con mayor profundidad. Durante la recuperación de este último tránsito, el narrador alude a cómo se ha producido una pérdida en el protagonista, la cual está vinculada principalmente con la enfermedad y el desprestigio político pero también con la lucha entre la esperanza y la resig- 


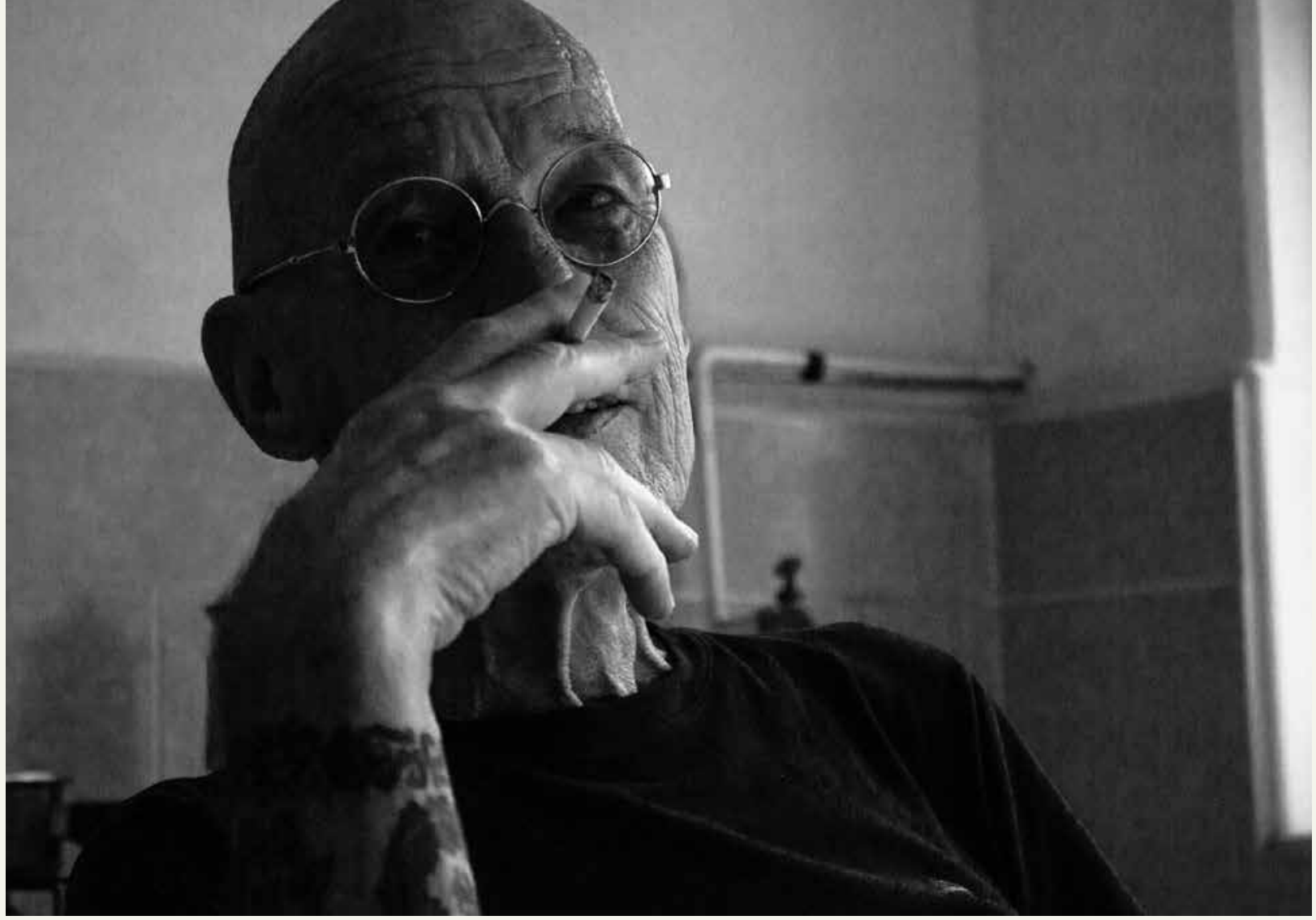

nación: el general, en condiciones precarias de salud, abandona Bogotá para sumergirse en un recorrido físico y memorístico, en el que lucha para no caer aniquilado por el mismo peso de sus hazañas pasadas. Enrique Gil Calvo, en Máscaras masculinas, menciona sobre esta transformación lo siguiente:

La vida masculina entera es una carrera contra el tiempo a largo plazo, tratando de trazar una trayectoria biográfica mínimamente digna. Y aquí la mejor metáfora es la ya citada del libro de la vida, de cuya lectura se desprende una historia natural: nacimiento, desarrollo, apogeo, declive y muerte. En el fondo, toda historia natural se parece a los libros titulados ascenso y caída (o auge y ocaso) del Imperio romano. Bien, pues basta con sustituir el Imperio romano por el imperio de un hombre: de cada
A lo largo de la novela aparecen numerosos fragmentos que dan cuenta de las aventuras que el general tenía con mujeres de diferentes nacionalidades. De entre todas ellas, destaca Manuela Sáenz, mujer impetuosa que participó activamente en el proceso de independencia.

hombre, obligado como está a dejar huellas de su paso por esta vida. $(2006,94)$

Dentro de la configuración de esta trayectoria masculina, una de las marcas más preponderantes es la relación que el Libertador establecía con las mujeres. A lo largo de la novela aparecen numerosos fragmentos que dan cuenta de las aventuras que el general tenía con mujeres de diferentes nacionalidades. De entre todas ellas, destaca Manuela Sáenz, mujer impetuosa que participó activamente en el proceso de independencia y fue la acompañante que apoyó y defendió al Libertador durante varios años hasta el exilio y la muerte de este. La relación entre Manuela y Bolívar es muy interesante desde múltiples perspectivas, pero en lo referente a la masculinidad, podría decirse que hay un equilibro entre las fuerzas que ambos representan. En este sentido, si bien Manuela pierde su poder en Bogotá y es enviada al exilio también después de la muerte del Libertador, no cabe duda de que sin su presencia el general no habría podido alcanzar varios de sus objetivos, entre los cuales figura la preservación de 
los principales rasgos que se toman en cuenta para señalar su declive. Con esto quiere decirse que, si bien hay una pérdida de poder por el rechazo de la clase política colombiana, el Libertador se percibe aún más disminuido en su dominio debido a la afectación de su corporalidad. Puede afirmarse que esto es una estrategia vinculada con la concepción de la masculinidad: recuérdese que el cuerpo del varón, al igual que el de la mujer, siempre es señalado como depositario de diversas sanciones y posturas sociales. Así, si el general está desprovisto de poder y su cuerpo ya no conserva la fortaleza anterior, se considera que la masculinidad estaría disminuida. Por ello el narrador de la novela insiste tanto en esta comparación del antes y el después en cuanto al cuerpo del Libertador. Un ejemplo de esto ocurre con el baile, una de las aficiones más conocidas de Bolívar:

Bailó casi tres horas, haciendo repetir la pieza cada vez que cambiaba de pareja, tratando quizás de reconstituir el esplendor de antaño con las cenizas de sus nostalgias. Lejos quedaban los años ilusorios en que todo el mundo caía rendido, y solo él seguía bailando hasta el amanecer con la última pareja en el salón desierto. Pues el baile era para él una pasión tan dominante, que bailaba sin pareja cuando no la había, o bailaba solo con la música que él mismo silbaba, y expresaba sus grandes júbilos subiéndose a bailar en la mesa del comedor. La última noche en Honda tenía ya las fuerzas tan disminuidas, que debía restablecerse en los intermedios aspirando los vapores del pañuelo embebido en agua de colonia, pero bailó con tanto entusiasmo y con una maestría tan juvenil, que sin habérselo
La corporalidad del

Libertador iba de la mano con el poder que representaba frente al resto de la población y resulta interesante advertir cómo, una vez que se inician los estragos por los padecimientos de salud, es uno de los principales rasgos que se toman en cuenta para señalar su declive.

propuesto desbarató las versiones de que estaba enfermo de muerte. (74-75)

Como puede observarse, la comparación permite señalar esas ausencias corporales del general, quien, a pesar de sus padecimientos, intenta sobreponerse y trata de brindar aún una imagen de fuerza. Esto sucede a lo largo de toda la novela hasta el momento en que el Libertador cae postrado y ya no tiene la capacidad de exhibirse con gallardía ante los demás. Gil Calvo menciona, cuando habla de la relación entre el héroe y la masculinidad, una concepción que se vincula con lo señalado en la cita anterior y durante todo el desarrollo de la novela:

Un héroe ha de controlar en todo momento su temor ante la propia muerte, fuente de pánico cerval y causa última de toda cobardía. El miedo a morir no desaparece nunca, pero al menos se puede aprender a convivir con él sin que interfiera en la propia capacidad de acción. Y a eso se le llama valor o valentía, que solo suele ser una máscara hueca y vacía imposible de refutar. Pues si el héroe está bien entrenado para ocultarlo, su miedo secreto se hace invisible desde el exterior, como si lo hubiera vencido para siempre. (160)

Y, efectivamente, el tipo de héroe al que nos enfrentamos en la novela ha aprendido a sobrellevar este miedo, que su ocultación es prácticamente un acontecimiento cotidiano. Solo durante los últimos momentos, cuando las fuerzas del general han menguado por completo, este opta por no ocultar más su padecimiento, aunque el miedo no necesariamente asoma por su mirada; es decir, conserva todavía una voluntad interna que se contrapone con su cuerpo debilitado.

Ahora bien, junto con la debilidad física viene a su vez, como ya se dijo, la caída del poder que arrastra al general al exilio tras una serie de traiciones e infamias que han quebrado la imagen del Libertador frente a su entorno político y la población en general. La figura mítica del héroe que había conquistado la independencia de varias naciones de Sudamérica ha sido sustituida por la de un dictador con sueños inalcanzables. De este modo, la posible hipermasculinidad del héroe -quien ha realizado hazañas monumentales, ha tenido bajo su dominio a una enorme cantidad de hombres dispuestos a servirle en cualquier momento y ha conquistado una cifra de mujeres que llenaría una inmensa lista- es disminuida por completo al verse obligado a abandonar su poder en medio de la inestabilidad política colombiana. Y, curiosamente, cuando está a punto de recuperar nuevamente el control de la nación, es su cuerpo enfermo el que 


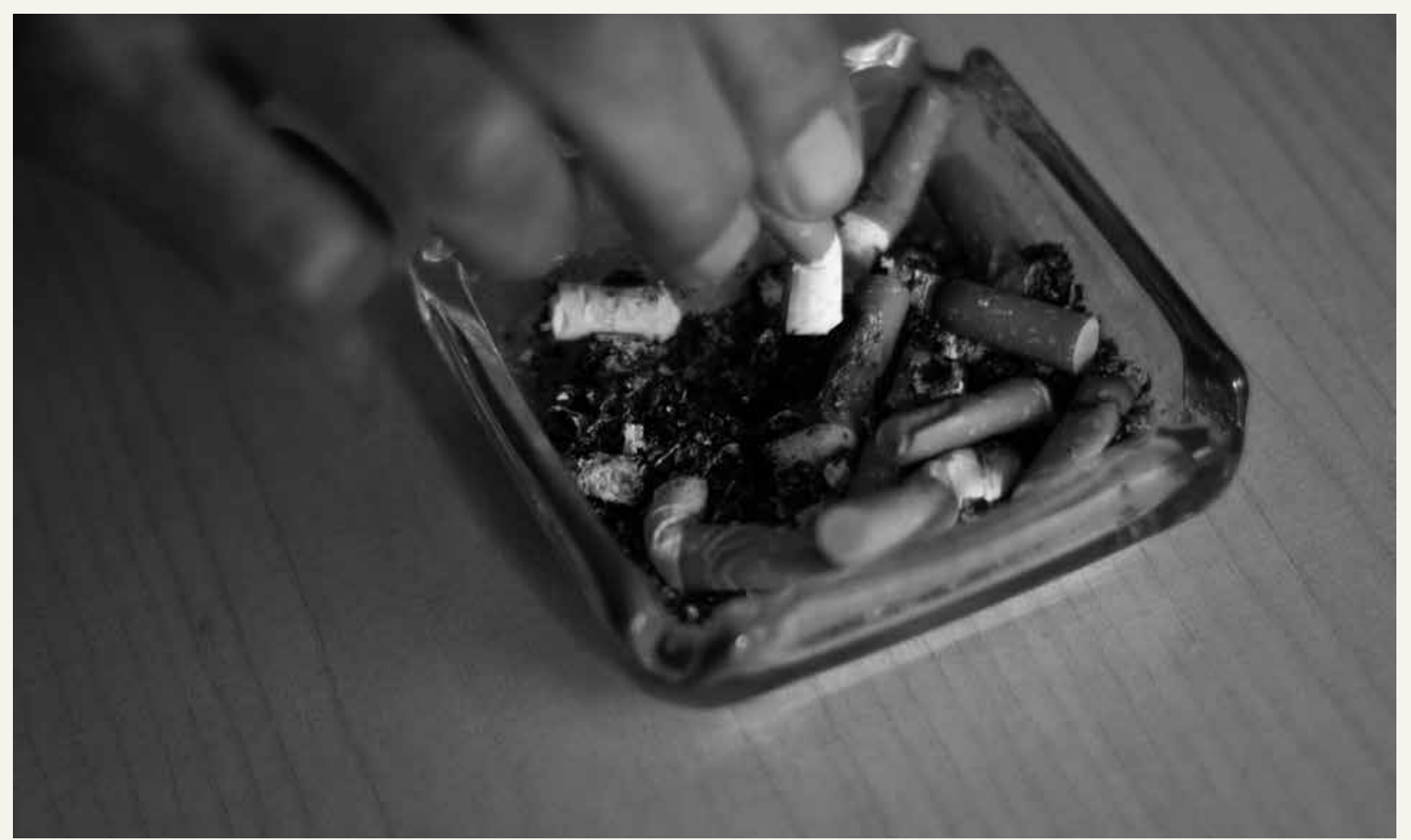

se lo impide, como si por diversos flancos quisiera ser detenido el proyecto pensado por el general.

Las diferentes facetas de la masculinidad del Libertador van entonces de la mano con la concepción del héroe. Los puntos tratados en este breve acercamiento permiten observar cómo el comportamiento con las mujeres, la corporalidad, la fuerza, la evasión del temor a la muerte, el dominio frente a otros varones, la gallardía y el control político impulsan aún más la imagen de un "súper hombre”, el cual, por la función moral que representa frente a los demás, debe evitar el declive. En consecuencia, los últimos meses del general aparecen marcados por una angustia constituida tanto desde el exterior como desde el interior: en el primer caso se trata de un temor al complejo destino de las naciones independientes; el segundo
El laberinto habitado por el Libertador se hace interminable cuando las exigencias sociales, históricas y políticas lo colocan a merced de la terrible mirada de los otros.

ble entre la enfermedad y la voluntad de sobreponerse a ella. Así, el laberinto habitado por el Libertador se hace interminable cuando las exigencias sociales, históricas y políticas lo colocan a merced de la terrible mirada de los otros. En este sentido, las contiendas del general parecen no tener conclusión, ya que prevalecen en su interioridad al obligarlo a equilibrar sus anhelos con los de los demás; por ello, la figura del héroe termina por convertirse en una piedra enorme que debe ser llevada con estoicismo a la par que se evita perder, a toda costa, la máscara de la masculinidad. LPyH

\section{REFERENCIAS}

García Márquez, Gabriel. 2006 [1988]. El general en su laberinto. México: Diana.

Gil Calvo, Juan. 2006. Máscaras masculinas: héroes, patriarcas y monstruos. Barcelona: Anagrama.

Víctor Saúl Villegas Martínez es maestro en Literatura Mexicana por la UV y doctor en Humanidades (línea de Teoría Literaria) por la UAMIztapalapa. Actualmente es profesor de la Facultad de Letras Españolas de la UV y miembro del sNI. 